\section{UAB} de Barcelona
Universitat Autònoma

\section{Dipòsit digital \\ D/D de la UAB}

This is the accepted version of the article:

Albonico, Alice; Kalyvitis, Sarantis; Pappa, Evi. Capital Maintenance and Depreciation over the Business Cycle. DOI 10.1016/j.jedc.2013.12.008

This version is avaible at https://ddd.uab.cat/record/203674

under the terms of the (cc) Br-NC-ND license 


\title{
Capital Maintenance and Depreciation over the Business Cycle*
}

\author{
Alice Albonico ${ }^{\dagger}$ \\ Sarantis Kalyvitis ${ }^{\ddagger}$ \\ University of Pavia \\ Athens University of Economics and Business \\ Evi Pappa ${ }^{\S}$ \\ European University Institute, UAB, and CEPR
}

April 2013

\begin{abstract}
This paper develops and estimates a stochastic general equilibrium model with capital maintenance, which affects endogenously the depreciation rate of capital. The estimate of maintenance series is found to track survey-based measures for Canada quite closely and to generate the procyclical pattern of maintenance observed in the data. We use it to infer the time profile of equipment capital depreciation in Canadian and US manufacturing. Contrary to existing estimates, the depreciation rate is estimated to be volatile and highly procyclical over the last 50 years in both countries.
\end{abstract}

JEL classification: E22, E32, E37.

Keywords: real business cycle, endogenous capital depreciation, maintenance.

\footnotetext{
*An online appendix of the paper is available at http://www.eui.eu/Personal/Pappa/research.html

${ }^{\dagger}$ University of Pavia, Department of Economics and Management, via S. Felice 5, 27100 Pavia, Italy. E-Mail: alice.albonico@eco.unipv.it.

${ }_{\ddagger}^{\ddagger}$ Athens University of Economics and Business, Department of International and European Economic Studies, Patission Street 76, Athens 10434, Greece. Email: skalyvitis@aueb.gr.

$\S$ European University Institute, Universitat Autonoma de Barcelona and CEPR, Department of Economics, Villa San Paolo, Via della Piazzuola 43, 50133 Florence, Italy. E-mail: evi.pappa@eui.eu.
} 


\section{Introduction}

Casual empiricism suggests that expenditures on capital maintenance constitute an integral part of the capital accumulation process. Broadly, outlays on capital maintenance cover the "deliberate utilization of all resources that preserve the operative state of capital goods" (Bitros, 1976) and as pointed out by Feldstein and Foot back in 1971, according to a survey on planned investment in the US for the period 1949-68, roughly one half of 'gross' investment concerned funds aiming at maintaining the operative state of capital goods ('replacement and modernization') as opposed to 'new' investment ('expansion'). Capital maintenance is, thus, directly related to capital depreciation and, in this vein, a series of papers have investigated the firm's problem between the optimal maintenance level and the maintenance-dependent capital depreciation rate. ${ }^{1}$

In turn, McGrattan and Schmitz (1999) were the first to provide a detailed picture on the size of aggregate capital maintenance using evidence from the Canadian survey on Capital and Repair Expenditures, which is globally the only source of aggregate long-run data on capital expenditures in newly purchased assets ('new' investment) and maintenance. According to this survey, total (private and public) maintenance and repair expenditures in Canada amounted on average to around $6.3 \%$ of GDP for the period 1956-93. This number was roughly equal to one third of spending on 'new' investments and, when compared to other so called 'engines of growth', was somewhat lower than education spending (6.8\% of GDP), but far above the average spending on R\&D $(1.4 \%$ of GDP) over the same period, suggesting that maintenance expenditures are 'too big to ignore'.

This paper develops and estimates a Dynamic Stochastic General Equilibrium (DSGE) model, in which capital maintenance affects endogenously the depreciation rate of capital along with capital utilization. Our model is found to perform well in replicating key stylized facts and allows us to assess, for the first time, the time profile of endogenous

\footnotetext{
${ }^{1}$ See, among others, Schmalensee (1974), Nickell (1978), Schworm (1979) and Parks (1979) for early contributions in this literature. Also, some empirical studies at the sectoral level have confirmed that capital deterioration is affected by maintenance expenditures; see Nelson and Caputo (1997) and the references cited therein for a brief survey of the empirical findings.
} 
capital depreciation based on a general equilibrium framework. Several studies have attempted to estimate the depreciation rate, mainly in US manufacturing, using various econometric approaches within single or multi-equation empirical setups (see Epstein and Denny, 1980; Hulten and Wykoff, 1981a, 1981b; Nadiri and Prucha, 1996a, 1996b; Jorgenson, 1996; Huang and Diewert, 2011). The general claim in the literature is that the depreciation rate has been fairly stable and that a constant depreciation rate may be a valid approximation for empirical work. In contrast to this evidence, our results indicate that the implied depreciation rate for equipment capital in Canadian and US manufacturing has exhibited substantial volatility over the last 50 years with a highly procyclical pattern.

The new element that drives the time profile of capital depreciation is the behavior of capital maintenance. In contrast to investment spending, which is typically captured by fixed non-residential private investment on property, plant and equipment, obtained from national accounts, or the Penn World Tables, or capital outlays from panel data for twodigit or plant-level manufacturing firms (often obtained from the US Compustat Industrial database), capital maintenance is mainly performed by employees. Hence there are no recorded market transactions, whereas maintenance and repair services purchased by firms in the market are typically treated as transactions involving intermediate goods. Thus, although maintenance activities are included in measured real output, their magnitude cannot be recovered by standard sources, like national accounting systems. Given these considerations, in this paper we use the 'Capital and Repair Expenditures' survey to obtain series on maintenance and 'new' investment of equipment capital in the Canadian manufacturing sector, which covers a period of 50 years (1956-2005). During this period total expenditures in 'new' investment and maintenance amounted on average to $16.7 \%$ of manufacturing output with an average share of maintenance over total investment of $36.1 \%$, accounting for $6 \%$ of output and $4.9 \%$ of the capital stock. Turning to the cyclical properties of the data, we observe that maintenance expenditures are procyclical, in accordance with the evidence reported by McGrattan and Schmitz (1999). Figures (1a) and (1b) plot spending on capital maintenance and the associated maintenance to 
capital ratio (henceforth, $M K$ ratio) versus manufacturing output. Both measures of maintenance are strongly procyclical. ${ }^{2}$

In light of this evidence we introduce within an otherwise standard Real Business Cycle (RBC) setup the assumption that capital outlays comprise, apart from 'new' investment that adds directly to the capital stock, maintenance expenditures that affect the capital decay rate. We then employ a general specification for the depreciation function that also embeds the effect of capital utilization on depreciation, as in Burnside and Eichenbaum (1996), and we use Bayesian techniques to estimate the structural parameters of the model with aggregate data from Canadian manufacturing covering the period 1956-2005. The model is able to generate estimates for capital maintenance expenditures that mimic reasonably well the cyclical behavior of actual survey-based series for Canada. Given the success of the model for Canada we also obtain consistent estimates for capital maintenance in the US over the period 1958-2009, a period for which there has been no systematic data collection on this type of outlays. ${ }^{3}$ We then use these estimates to obtain the time profile of the depreciation rate of equipment capital in Canadian and US manufacturing over the business cycle.

We close the introductory section by noting that so far very few DSGE macroeconomic models have attempted to endogenize maintenance outlays. Early contributions in this literature can be found in Licandro and Puch (2000) and Collard and Kollintzas

\footnotetext{
${ }^{2}$ Descriptive statistics point towards a contemporaneous correlation between maintenance and $M K$ ratio with output of 0.63 and 0.60 , respectively. This correlation seems to be higher in the first part of the sample: for the period 1956-1983 the corresponding correlation coefficients amount to 0.85 and 0.86 . The cross-correlations, which are available upon request, remain high for lags (-1) to (-3) of output for both maintenance and $M K$ ratio. A full description of the data sources used in the paper is presented in the Data Appendix. All series are in logs and have been detrended with the HP filter $(\lambda=100$ for annual data).

${ }^{3}$ We note that the US Census Bureau has added in the Annual Survey of Manufacturers entries on Repair and Maintenance services of buildings and/or machinery for the years 2007, 2008, and 2009. The definition includes payments on purchased services for all maintenance and repair work on buildings and equipment. Payments made to other establishments of the same company and for repair and maintenance of any leased property also are included. Excluded are extensive repairs or reconstruction that was capitalized, which is considered capital expenditures, costs incurred directly by the establishment in using its own work force to perform repairs and maintenance work, and repairs and maintenance provided by the building or machinery owner as part of the rental contract. 'New' investments and maintenance account on average for $8.7 \%$ of total (equipment and structures) US manufacturing output, with maintenance amounting to $20.9 \%$ of total investment.
} 
(2000). However, in both studies maintenance moves countercyclically, which contradicts the stylized facts depicted in McGrattan and Schmitz (1999). In turn, some papers have investigated how investment and maintenance respond to technology shocks, a feature that is crucial for the complementarity/substitutability between these two types of capital outlays (Boucekkine and Ruiz-Tamarit, 2003; Saglam and Veliov, 2008; Boucekkine et al., 2009). Boucekkine et al. (2010) examine the short-run responses of investment and maintenance and find that they move in the same direction following technology shocks, thus, suggesting that they act complementary to each other. We provide some insights in this literature by showing that maintenance and output tend to move in the same direction in response to Total Factor Productivity (TFP) shocks, but in opposite directions in responses to investment-specific shocks.

The rest of the paper is organized as follows. Section 2 presents the model. Section 3 discusses the results from the Bayesian estimation and presents the model dynamics. Section 4 presents the estimates for the time profile of capital depreciation in Canada and the US. Finally, section 5 concludes.

\section{The model}

In the model economy households maximize a utility function with two arguments (goods and labor effort) over an infinite life horizon. Households rent effective capital services to firms and allocate their spending on capital between 'new' investment, which adds directly on the capital stock, and capital maintenance, which affects along with capital utilization the depreciation rate. In this section we present the main features of the model and its solution.

\subsection{Households}

The economy is inhabited by infinitely lived agents that derive utility from consumption, $C_{t}$, and disutility from hours worked, $h_{t}$, at each period $t$. The present-value utility of 
the household is given by:

$$
\mathrm{E} \sum_{t=0}^{\infty} \beta^{t} \eta_{t}^{u}\left[\frac{C_{t}^{1-\sigma}}{1-\sigma}-\lambda_{n} \eta_{t}^{h} \frac{h_{t}^{1+\theta_{n}}}{1+\theta_{n}}\right]
$$

where $\sigma>0$ is the risk aversion coefficient, $\theta_{n}>0$ determines the supply elasticity of hours, and $\lambda_{n}>0$ is a preference parameter. Parameter $\beta$ is a subjective discount factor with $0<\beta<1$ and $\mathrm{E}$ is the expectation operator. $\eta_{t}^{u}$ and $\eta_{t}^{h}$ represent a preference shock and a labor supply shock, respectively; both shocks are assumed to follow an $\operatorname{AR}(1)$ process with i.i.d. normal error term: $\log \left(\eta_{t}^{u} / \eta^{u}\right)=\rho_{u} \log \left(\eta_{t-1}^{u} / \eta^{u}\right)+\epsilon_{t}^{u}$ and $\log \left(\eta_{t}^{h} / \eta^{h}\right)=$ $\rho_{h} \log \left(\eta_{t-1}^{h} / \eta^{h}\right)+\epsilon_{t}^{h}$. The literature has indicated both labor supply and preference shocks as key determinants for business cycle fluctuations and for that reason we include them as possible sources of fluctuations in our analysis.

The representative household owns the capital stock and receives income from renting the effective capital stock (capital services), $U_{t} K_{t}$, where $U_{t}$ is the utilization rate of the capital stock $K_{t}$, to the firm at a rate $r_{t}$ and from working at a wage rate $w_{t}$. The household allocates her income stream between consumption $C_{t}$, 'new' investment $I_{t}$, and capital maintenance $M_{t}$ :

$$
C_{t}+I_{t}+M_{t} \leq w_{t} h_{t}+r_{t} U_{t} K_{t}
$$

The rate at which capital depreciates depends positively on its utilization and negatively on maintenance expenditures. 'New' investment, $I_{t}$ is related to the capital stock accumulation by:

$$
Z_{t} I_{t}=K_{t+1}-\left(1-\delta\left(U_{t}, \frac{M_{t}}{K_{t}}\right)\right) K_{t}+v\left(\frac{K_{t+1}}{K_{t}}\right) K_{t}
$$

where $\delta($.$) is the depreciation function and v($.$) is a function of gross investment regulating$ capital adjustment costs. The variable $Z_{t}$ represents an investment-specific technology shock that affects the capital law of motion and can be embodied either in the investment good (like technology advances) or in the process for producing it, thus affecting the real price of investment. Greenwood et al. (1997, 2000) have shown that technology shocks 
involving investment-specific rather than neutral technological change can be a major source of the business cycle. Fisher (2006) shows that the combined impact of neutral and investment-specific shocks is important in explaining fluctuations of output and labor in the US with investment-specific shocks mattering more than TFP shocks. As a result, including investment-specific shocks in the analysis is crucial for studying the dynamics of maintenance. We model the investment-specific shock as an AR(1) process with i.i.d. normal error term: $\log \left(Z_{t} / Z\right)=\rho_{z} \log \left(Z_{t-1} / Z\right)+\epsilon_{t}^{z}$.

Following the standard approach, we adopt a quadratic specification for the capital adjustment costs function:

$$
v\left(\frac{K_{t+1}}{K_{t}}\right)=\frac{b}{2}\left(\frac{K_{t+1}}{K_{t}}-1\right)^{2}
$$

where $b>0$ is a parameter measuring the degree of capital adjustment $\operatorname{costs}^{4}$.

As in McGrattan and Schmitz (1999), we assume that depreciation is a decreasing function of maintenance expenditure, so that as maintenance services per unit of the capital stock increase, the rate at which capital depreciates decreases. Following Greenwood et al. (1988) and Burnside and Eichenbaum (1996) we also allow depreciation to be an increasing function of capital utilization. Given these assumptions, the depreciation function is parameterized as:

$$
\delta\left(U_{t}, \frac{M_{t}}{K_{t}}\right)=\xi\left[\psi U_{t}^{\phi}+(1-\psi) e^{-\gamma \frac{M_{t}}{K_{t}}}\right]^{\theta}
$$

The parameters $\phi$ and $\gamma$ assess the effect of utilization and maintenance on the rate of depreciation of capital, respectively. In particular, $\phi>0$, so that $\frac{\partial \delta}{\partial U}>0$. In the next section, we estimate the value of $\gamma$ with Bayesian techniques. If $\gamma>0$, we have that $\frac{\partial \delta}{\partial M}<0$, and $\frac{\partial^{2} \delta}{\partial M^{2}}>0$. When $\phi=0$, capital utilization does not affect the rate at which capital depreciates, while with $\gamma=0$ maintenance expenditures are ineffective in reducing the capital depreciation rate. Moreover, when the capital stock is not utilized and maintenance expenditures are very high, there is no depreciation, i.e. $\delta(0, \infty)=0$.

\footnotetext{
${ }^{4}$ Note that our results hold when adjustment costs are assumed to depend on investments.
} 
Notice that the specification adopted in (5) nests the one in McGrattan and Schmitz (1999) for $\psi=0$ and the one in Burnside and Eichenbaum (1996) for $\psi=1$. When the benchmark model without endogenous maintenance is considered, the depreciation function takes the form $\delta\left(U_{t}\right)=\delta U_{t}^{\phi}$, in line with Greenwood et al. (1988) and Burnside and Eichenbaum (1996).

Given the trade-off between the production benefits and the depreciation costs of capital utilization, the agent will in general not find it optimal to fully utilize the capital stock. Under our assumptions there is also a trade-off in allocating resources between 'new' investment $I_{t}$ and capital maintenance $M_{t}$, which will be determined by their respective returns and the effects of the various shocks in the model. ${ }^{5}$

\subsection{Production side and market clearing}

Firms use capital services and labor hours to produce a final good, $Y_{t}$, that can be used for consumption, investment and maintenance activities. The representative firm then chooses its factor inputs, hours worked, $h_{t}$, and capital services, $U_{t} K_{t}$, to produce a given level of $Y_{t}$ in order to minimize the production costs:

$$
w_{t} h_{t}+r_{t} U_{t} K_{t}
$$

subject to the technological constraint:

$$
Y_{t}=\left(U_{t} K_{t}\right)^{1-\alpha}\left(X_{t} h_{t}\right)^{\alpha}
$$

where the variable $X_{t}$ represents a neutral labor-augmenting technology (TFP) shock, with an $\mathrm{AR}(1)$ process with i.i.d. normal error term: $\log \left(X_{t} / X\right)=\rho_{x} \log \left(X_{t-1} / X\right)+\epsilon_{t}^{x}$.

\footnotetext{
${ }^{5}$ As described in Boucekkine and Ruiz-Tamarit (2003) and Boucekkine et al. (2010), the sign of the cross derivative $\frac{\partial^{2} \delta}{\partial M \partial U}$ is crucial to determine the degree of complementarity or substitutability between investment series and maintenance. The sign of this derivative is determined by the size of parameter $\theta$ : when $\theta>1(\theta<1)$ the cross derivative is negative (positive). In the steady state the value of $\theta$ depends on the estimated values of parameters $\gamma, \phi$ and $\alpha$. When we move to posting our priors we opt for values that allow $\theta$ to be bigger or smaller than one and let the data decide on its magnitude.
} 
In equilibrium the goods market clears and we have:

$$
Y_{t}=C_{t}+I_{t}+M_{t}+G_{t}
$$

where $G_{t}$ is a public spending shock, whose logarithm follows an $\mathrm{AR}(1)$ process with i.i.d. normal error term: $\log \left(G_{t} / G\right)=\rho_{g} \log \left(G_{t-1} / G\right)+\epsilon_{t}^{g}$.

\subsection{Model solution}

The representative agent chooses a sequence of $C_{t}, h_{t}, U_{t}, I_{t}$, and $M_{t}$, to maximize (1) subject to (2) and (3). The first-order conditions of the model are given by the following equations::

$$
\begin{aligned}
& \eta_{t}^{h} \lambda_{n} h_{t}^{\theta_{n}}=\alpha C_{t}^{-\sigma} \frac{Y_{t}}{h_{t}} \\
& (1-\alpha) \frac{Y_{t}}{U_{t}}=\xi \theta \phi \psi\left[\psi U_{t}^{\phi}+(1-\psi) e^{-\gamma \frac{M_{t}}{K_{t}}}\right]^{\theta-1} \frac{K_{t}}{Z_{t}} U_{t}^{\phi-1} \\
& \xi \theta \gamma(1-\psi)\left[\psi U_{t}^{\phi}+(1-\psi) e^{-\gamma \frac{M_{t}}{K_{t}}}\right]^{\theta-1} e^{-\gamma \frac{M_{t}}{K_{t}}}=Z_{t} \\
& \beta E_{t}\left\{\eta_{t+1}^{u} C_{t+1}^{-\sigma}\left[r_{t+1} U_{t+1}-\frac{M_{t+1}}{K_{t+1}}+\frac{1-\delta\left(U_{t+1}, \frac{M_{t+1}}{K_{t+1}}\right)}{Z_{t+1}}+\frac{\frac{b}{2}\left(\left(\frac{K_{t+2}}{K_{t+1}}\right)^{2}-1\right)}{Z_{t+1}}\right]\right\} \\
& =\eta_{t}^{u} \frac{C_{t}^{-\sigma}}{Z_{t}}\left[1+b\left(\frac{K_{t+1}}{K_{t}}-1\right)\right]
\end{aligned}
$$

Equation (9) gives the first-order condition for hours worked and equation (10) sets the marginal return of a rise in the capital utilization rate equal to its opportunity cost measured by the increased capital depreciation rate. Equation (11) is the optimality 
condition with respect to maintenance and sets the marginal benefit of maintenance arising through the depreciation rate equal to its cost. Finally, equation (12) modifies the usual optimality condition that equates the marginal productivity with the user cost of capital, as a marginal increase in the capital stock implies a rise in its required maintenance cost. Firms set the marginal products of effective capital and hours worked equal to the return of capital and the wage rate, respectively.

In order to investigate the dynamics of the model, we log-linearize the equilibrium conditions around the steady state. The detailed steady-state conditions and the loglinear equations are presented in the Appendix.

\section{Estimation and dynamics}

\subsection{Bayesian estimation}

\subsubsection{Data and priors}

The log-linearized model is estimated with Bayesian techniques. We estimate the mode of the posterior distribution by maximizing the log posterior function, which combines the prior information on the parameters with the likelihood of the data, using the numerical method by Sims (1999). ${ }^{6}$ The Metropolis-Hastings algorithm is then used to get the complete posterior distribution with a sample of 250000 draws (dropping the first $20 \%$ draws) and a scale for the jumping distribution of 0.4 ( 0.5 for the US).

The set of observable variables for Canada comprises five annual series over the period 1956-2005, namely output, utilization, total investment, consumption, and hours worked. Maintenance expenditures are not included in the set of observable variables, but are, instead, estimated in order to evaluate the model's performance. Due to data availability and in order to maintain consistency among the variables used, all series refer to the manufacturing sector. Output, total investment and consumption are deflated with the Industrial Selling Price index and divided by total working population. Hours are adjusted

\footnotetext{
${ }^{6}$ See Smets and Wouters (2007).
} 
for total working population. The discount factor is fixed at 0.98, in line with a steadystate real interest rate of $2 \%$. The steady-state depreciation rate, which corresponds to the steady-state 'new' investment to capital ratio, is set to 0.0882 and the steady-state $M K$ ratio is set at 0.0494 . Both figures equal the corresponding averages of the series from the Canadian Survey on Capital and Repair Expenditures. ${ }^{7}$ The ratio of public spending on GDP is fixed at $17 \%$. In turn, we use steady-state relationships to determine the values of parameters $\theta, \xi$ and $\psi$, and estimate the values for $\phi$ and $\gamma$ (see Appendix A.1 for details). Table 1 displays the fixed parameters and their steady-state values.

The same approach is used to estimate the model for the US. Data on US manufacturing output, employment, hours worked, capital expenditures, and capital are obtained from the NBER-CES Manufacturing Industry Database, provided by Becker and Gray (2009), which covers the period 1958-2005. The series are extended to 2009 using the corresponding entries reported in the U.S. Census Annual Survey of Manufacturers. A series on capital utilization in U.S. manufacturing is compiled using data from the Board of Governors of the Federal Reserve System. The steady-state depreciation rate, which equals to steady-state investment to capital ratio, is derived as the average of the series for manufacturing machinery and equipment over the sample and is set to $0.117 .{ }^{8}$ The steady-state $M K$ ratio is obtained by multiplying this value by the average maintenance to investment ratio for the available US data for total manufacturing, thus obtaining 0.0309 for the machinery and equipment sector. The rest of the parameters are determined as in the exercise with Canadian data.

All other deep parameters and the processes governing the five structural shocks are estimated with Bayesian techniques. We assume the same priors for estimating the model

\footnotetext{
${ }^{7}$ The figure for the steady-state depreciation rate is in line with the estimate reported by Hwang (2002/3) on the average depreciation rate for machinery-equipment in Canadian manufacturing (8.2\%).

${ }^{8}$ This figure is in line with estimates of capital depreciation rates in US manufacturing. Epstein and Denny (1980) account for endogenous utilization and find an average depreciation rate of $12.6 \%$ over the period 1947-1971. Hulten and Wykoff (1981) report a depreciation rate of $13.3 \%$ for equipment. Nadiri and Prucha (1996a) report an average depreciation rate of 5.9\% in US manufacturing over the period 1960-1988. Jorgenson (1996) reports an average depreciation rate of $15 \%$ for durable equipment in US manufacturing, whereas similar figures are reported by Fraumeni (1997). Kollintzas and Choi (1985) and Bischoff and Kokkelenberg (1987) report values of $12.5 \%$ of $10.6 \%$ respectively.
} 
for both US and Canadian data. We set most of the priors following existing calibration exercises and describe positive parameters with normal or Gamma distributions. In particular, the intertemporal elasticity of substitution, $\sigma$, is usually calibrated in the $[0.5,6]$, with lower values typically estimated form microeconometric data, we allow $\sigma$ to vary in the $(0,6)$ interval. The inverse of the Frisch elasticity of labor supply, $\theta_{n}$, is estimated to be low in microeconomic studies and RBC models use much higher values for this elasticity, we let $\theta_{n}$ vary in the $(0,10)$ interval. The calibrated values of the adjustment cost parameter, $b$, vary from values around 3 (Woodford, 2003) to 19 (Casares and McCallum, 2006); we assume here a prior in the $(0,10)$ interval for this parameter. The interval for the share of labor, $\alpha$, in the production function is centered about the standard calibrated value for this parameter and is represented by a normal distribution. The parameter of the depreciation function $\gamma$ and parameter $\phi$, which determines the elasticity of depreciation to changes in capital utilization, are described by Gamma distributions. Given the absence of calibrated values for parameter $\gamma$ we assume a relatively diffused prior, whereas existing empirical estimates include low values for parameter $\phi$. Basu and Kimball (1997) estimate a log-linear production function incorporating variations in both capital utilization and effort for a panel of US firms from 21 manufacturing industries for the period 1949-1985 and estimate $\phi$ to be approximately unity. They stress, however, that the data are not very informative about this parameter. The $95 \%$ confidence interval of $[-0.2,2]$ indicates that the data cannot reject even infinitesimally small values of $\phi$, although the negative values should be eliminated on purely economic grounds. Burnside and Eichenbaum (1996) calibrate $\phi=1.56$, while Neiss and Pappa (2005) calibrate a slightly higher value for this parameter. We set the mean of $\phi=0.9$ with a standard deviation of 0.2 . The persistence parameters of the $\mathrm{AR}(1)$ processes are Beta distributed and the standard errors of the innovations are assumed to follow an Inverse-gamma distribution. Prior shapes, prior means and standard deviations are collected in Table 2. 


\subsubsection{Posterior estimates}

The left panel of Table 3 shows the estimation results of the model for Canada. The first column displays results for the standard RBC model and the second panel displays results for the maintenance model, reporting the posterior mean and $90 \%$ credible intervals for each estimated parameter. The data appear to be very informative. ${ }^{9}$ Regarding the shocks considered, all exhibit low persistence with the labor supply shock displaying the highest persistence and the preference and government spending shocks being the least persistent. Standard deviations of the shocks are estimated to be low. As for the structural parameters of the model, the mean of the posterior distribution is typically not far from the mean of the priors. For example, the posterior mean of the intertemporal elasticity of substitution equals 3.20. Moreover, all the posterior estimates assume economically plausible values. The posterior mean for $\theta_{n}$ equals 2.05, which implies a Frisch elasticity of 0.49 . This number is in the interval $(0.01,0.85)$ of the values estimated in microeconomic studies for Canada. ${ }^{10}$ The posterior value for the labor share is somewhat higher than the initial value but remains within reasonable bounds.

Turning to the parameters of the depreciation function, the posterior value of parameter $\phi$ is slightly higher than the prior value and the posterior estimate for parameter $\gamma$ is positive and above its postulated prior, confirming that as maintenance expenditures increase the depreciation rate decreases. For these values of $\gamma, \phi$, and $\alpha$, the implied value for parameter $\theta$ equals 2.25, whereas the implied values for $\psi$ and $\xi$ are, respectively, 0.52 and 0.19 . These estimates imply that when capital is fully utilized and there are no expenditures in maintenance, the capital stock depreciates at the rate $\xi=19 \%$. When capital is not utilized and there are no maintenance expenditures, the depreciation rate equals $\xi(1-\psi)^{\theta}=3.7 \%$, which forms the estimated "natural" rate of depreciation. When the capital stock is fully utilized and maintenance expenditures are very high the

\footnotetext{
${ }^{9}$ Overall, the posterior distributions are normally shaped. We assess the reliability of our estimates through Monte Carlo Markov Chains univariate and multivariate diagnostics (Brooks and Gelman, 1998). This analysis proves that the results are sensible, as the moments of the parameters appear to be constant and converging.

${ }^{10}$ See Evers et al. (2008) for a summary of such estimates.
} 
depreciation rate of the capital stock equals $\xi \psi^{\theta}=4.4 \%$.

The right panel of Table 3 presents the corresponding estimates for the US, which differ somehow from their Canadian counterparts. First, the variances of the shocks, with the exception of the TFP shock, assume much lower values in the US posteriors, whereas the estimated persistence of the shocks is also different. The preference shock is estimated to be more persistent in the US relative to Canada and the other shocks less persistent. The estimated values of $\sigma$ and $\theta_{n}$ in the US are substantially lower than their estimated values for Canada. This implies that both risk aversion and the labor supply elasticity need to take a higher value in order for the model to match the US data. The estimates of risk aversion for the US are within reasonable ranges, although the estimates for the Frisch elasticity imply a labor supply elasticity of 2.9. Given the US estimates for $\gamma$ and $\phi$, the implied values for the parameters of the depreciation function are: $\theta=2.73$, $\psi=0.58$ and $\xi=0.16$. Such values imply that the "natural" depreciation rate of US manufacturing capital equals $\xi(1-\psi)^{\theta}=1.5 \%$, which is lower than the corresponding Canadian rate.

The estimates of the maintenance model can be compared with estimates of a standard RBC model without capital maintenance keeping the same set of observables, calibrated parameters and priors for the two models. The only exception is parameter $\phi$ in the depreciation function, which is inherently different in the two models. When we contrast the log data densities in the two models for Canada and the US, the differences do not appear to be substantial. The model with endogenous maintenance for Canada attains a log data density of 462.7 , whereas the value for the standard model is 462.5 . The corresponding figures for the US are 477.0 and 473.8. However, differences in the posterior estimates for some parameters turn out to be substantial since endogenous maintenance expenditures provide an additional mechanism for dampening investments.

In particular, the elasticity of depreciation to changes in utilization, $\phi$, needs to be much higher in the standard RBC model in order to match the data. There is little knowledge about how utilization affects the depreciation of capital. As it was mentioned earlier estimates of phi are not very informative and vary in the $[0.7,3.2]$ interval (see, e.g., 
Basu and Kimball, 1997). Table 3 indicates that the calibration of $\phi$ is biased upwards when one does not consider the positive effects of maintenance in the depreciation of the capital stock. The absence of endogenous maintenance doubles the estimates of $\phi$ in the standard model. Notice that the presence of endogenous maintenance affects also the estimation of the relative risk aversion, $\sigma$. When risk aversion is lower, the willingness to intertemporally substitute is higher and consumption smoothing is less important. Given the absence of endogenous maintenance in the standard RBC model there is no mechanism apart from capital adjustment costs to smooth investment in equilibrium. For that reason, the estimates of relative risk aversion are lower in this case. In the standard RBC model estimated for Canada the lack of an investment smoothing mechanism is also reflected in the higher estimates for capital adjustment costs, parameter $b=9.02$ in comparison with $b=8.67$ in the model with endogenous maintenance. However, in the estimation of the two models using US data capital adjustment costs are estimated to be lower in the standard model relative to the endogenous maintenance model contradicting our intuition for the smoothing role of endogenous maintenance on investment dynamics. Yet, one has to recall that the estimated labor supply elasticity for the US data is six times larger than that of its Canadian counterpart. A higher labor supply elasticity implies that the economy can adjust to shocks using much more the labor margin and less so the utilization margin that comes at a cost of higher depreciation. As a result, the high labor supply elasticity dampens utilization movements and induces smaller movements in maintenance for correcting the detrimental effects of variable capital utilization in the depreciation rate. As a result, investment dynamics are dampened through less movement in utilization and there is no need of increasing capital adjustment costs for dampening the investment responses.

Hence, we can conclude that although models do not differ substantially in their overall fit, the presence of endogenous maintenance apart from generating more realistic values for the elasticity of marginal depreciation with respect to the utilization rate, can also achieve smaller variations in investment for realistic values of the labor supply elasticity and a lower degree of capital adjustment costs. 


\subsection{Model dynamics}

To gain some intuition on the workings of the model we present the dynamics of our model economy by comparing its impulse response functions (IRFs) with those generated by a standard RBC model with variable utilization calibrated with the obtained parameter estimates. In general, responses are similar and the presence of endogenous maintenance induces a relatively higher volatility of utilization and the depreciation rate since it can undo the detrimental effects of increased utilization in the depreciation function.

The first row of Figure 2 plots the estimated IRFs of the variables of interest to a onestandard-deviation shock to TFP. The productivity shock raises the marginal product of the production factors and, as a result, capital utilization, investment and capital increase in response to the shock generating a surge in output and consumption. Given the increase in utilization, the depreciation rate increases. Maintenance also increases to balance the detrimental effects of the surge in capital utilization on depreciation. Overall, the higher volatility of utilization in the maintenance model implies a higher volatility of depreciation, which is not counterbalanced by the rise in maintenance and translates also in higher volatility of capital.

The investment-specific shock affects the production of investment goods. The second row of Figure 2 presents IRFs of the two models in response to shocks in the price of investment. The fall in the price of investment does surge investment in the impact period, increasing capital and, due to complementarities in production, hours and capital utilization. In the model with maintenance, the fall in the price of investment increases also the relative price of maintenance. Agents find it optimal to decrease maintenance expenditures on impact, which further increases the depreciation rate. Notice that the response of maintenance to investment-specific shocks is crucial to identify this type of shocks in the short run. After an investment-specific shock maintenance expenditures are reduced on impact while output increases, while for the rest of the disturbances considered the two variables always comove. ${ }^{11}$

The third row of Figure 2 plots the IRFs to a negative labor supply shock. The shock

\footnotetext{
${ }^{11}$ This implication is general and does not depend on the exact parametrization of the model.
} 
reduces hours on impact and, due to factor complementarity in the production function, it also reduces capital utilization and investment. The fall in capital utilization reduces maintenance expenditures and the induced movements in utilization and maintenance reduce the depreciation rate in equilibrium.

The next row of Figure 2 shows that a positive preference shock crowds out investment and, as a result, reduces hours, capital, and capital utilization. Consequently output also falls in equilibrium. The fall in utilization decreases capital depreciation and the need for capital maintenance and maintenance falls also in equilibrium. In comparison to the standard RBC model, we notice again that the presence of maintenance indusces more sizeable utilization and depreciation responses.

Finally, the last row of Figure 2 presents the IRFs to a government spending shock. The increase in government spending crowds out investment, but, due to the induced negative wealth effect, it increases labor supply and capital utilization in equilibrium. The rise in capital utilization raises the depreciation of capital and maintenance expenditures increase as well. ${ }^{12}$

\section{The time profile of capital depreciation}

Given the importance of capital depreciation in empirical exercises and applications, in this section we apply our approach to analyze the inferred time profile of variable capital depreciation in Canadian and US manufacturing by endogenizing maintenance expenditures. Although several studies have attempted to estimate the depreciation rate (especially in US manufacturing) using various econometric approaches within single or multi-equation setups (see Epstein and Denny, 1980; Hulten and Wykoff, 1981a, 1981b; Nadiri and Prucha, 1996a, 1996b; Jorgenson, 1996; Huang and Diewert, 2011), there is no study that has provided estimates for depreciation series that are generated within a general equilibrium framework. An exception that uses time-varying depreciation within a general equilibrium setup is the study by Chen et al. (2006) who calibrate the Japanese

\footnotetext{
${ }^{12}$ A similar picture (available upon request) emerges from the impulse responses obtained for the US model.
} 
economy in order to investigate the driving forces of the saving rate. The time profile of their reported (exogenous) depreciation rates indicates that they were exceptionally high in the $50 \mathrm{~s}$ and $60 \mathrm{~s}$, but declined substantially over the following decades. Also, Liu at al. (2011) and Furlanetto and Seneca (2013) show that a reduced form depreciation shock is extremely important in fitting the business cycle. ${ }^{13}$

\subsection{Canada}

To perform the exercise, as a first step we assess the fit of our model by comparing model estimates for capital maintenance and the actual series from the Canadian Survey. Since we did not include actual series for maintenance in the estimation of our model this exercise should serve as an additional test of our specification. The Bayesian estimation uses the Kalman filter to obtain a state-space representation of the dynamic system and, through a recursive procedure, to derive the log-likelihood, conditional on the set of observables. The same recursive algorithm enables to sequentially update a linear projection for the system and as a by-product to generate smoothed estimates for the endogenous variables. Figure 3 displays the estimated trend deviations of the series for maintenance to capital ratio versus the actual trend deviations of the series from the Canadian Survey on Capital and Repair Expenditures. The model fits fairly well the pattern for the $M K$ ratio for most of the period covered with most of the peaks captured well by the estimated series, which are less volatile in general. The contemporaneous correlation between the actual and the estimated series amounts to 0.50. In line with their data counterpart, the estimated series are highly procyclical with the contemporaneous correlation of actual output and estimated maintenance equal to 0.66. Moreover, the cross-correlations remain high for lags $(-1)$ to $(-3)$ and for lead $(+1)$ of output, similarly to the actual series. ${ }^{14}$ To further assess the fit of our model we also calculate the ratio of maintenance to 'new' investment series for Canada, which are two key variables in our setup. The estimated

\footnotetext{
${ }^{13}$ Liu et al. (2011) view the depreciation shock as a shock to the quality of capital, in our framework the shock to depreciation could be a shock originating from changes in the effectiveness of maintenance to restore the value of the existing capital shock.

${ }^{14}$ Detailed cross-correlograms are available upon request.
} 
series are depicted in Figure 4. Again, our estimates track well the actual series: the correlation between actual and simulated series is $0.72 .{ }^{15}$

Using our theoretical framework we provide an estimate of the time profile of the depreciation rate of equipment capital in the Canadian manufacturing sector over the period 1956-2005 (centered at 8.82\%), which is depicted in Figure 5 along with actual output trend deviations. Table 4 contains the detailed figures for the depreciation rates of machinery-equipment capital in Canadian manufacturing. The depreciation rate of equipment capital is found to have a standard deviation of $1.2 \%$ and ranges between $5.4 \%$ and $11.3 \%$ over the period with a strongly procyclical profile: the correlation coefficient with output trend deviations amounts to 0.56 . The correlation is higher $(0.71)$ in the 1956-83 period of the sample, when output and $M K$ ratio exhibit a high correlation, and drops substantially (0.36) in the 1984-2005 period. This picture indicates that the long-run depreciation rate of equipment capital in Canadian manufacturing has exhibited substantial swings reflecting periods of fast and slow growth in the manufacturing sector and the associated pattern of capital maintenance. ${ }^{16}$

\section{$4.2 \quad$ US}

Given the success of the model in replicating the main features of the actual series of capital maintenance in Canadian manufacturing, we use our approach to estimate series for capital maintenance in the US manufacturing sector, where there has been no systematic collection of data on capital maintenance until 2007. Our estimates thus provide an assessment of the behavior of capital maintenance in the US over the last 50 years using the average value of years 2007-9 as a proxy of the steady-state maintenance to 'new'

\footnotetext{
${ }^{15}$ An implication derived from Figures 3 and 4 is that the endogenously determined capital stock in our model is too volatile and does not replicate the second moment of the official capital stock series. This is due to the fact that endogenous maintenance dampens the responses of investment and does not operate directly through the accumulation of capital. Instead, our model performs much better in estimating the second moment of investment series.

${ }^{16}$ We note that a straightforward extension would be to generate alternative capital stock series that can be contrasted with official capital stock estimates. However, the comparison would be internally inconsistent as the official capital stock series are created under a different set of assumptions than those maintained here.
} 
investment ratio. Figure 6 plots the estimated series for maintenance to capital ratio and output (in trend deviations) and Table 5 contains the estimated series of maintenance expenditures for machinery-equipment capital in US manufacturing for the period 19582009 expressed in current thousands USDs. ${ }^{17}$ As in the case of Canada, maintenance is found to be highly procyclical with a correlation coefficient of 0.85 with significant positive correlations also for the first lag and the first lead of output. The main picks and troughs of the business cycle are well captured by our measure of maintenance. A similar picture emerges for the maintenance to 'new' investment ratio (Figure 7), which is also procyclical with a correlation coefficient of 0.51 .

We use our estimated series for capital maintenance in US manufacturing to obtain an assessment of the magnitude and time profile of the depreciation rate in machineryequipment capital over the period 1958-2009 in the context of our DSGE model. Figure 8 plots the estimated depreciation rate and the output trend deviations for US manufacturing capital over the period 1958-2009 and Table 5 contains the detailed figures for the depreciation rates of machinery-equipment capital in US manufacturing. The picture indicates that, as in the case of Canada, the depreciation rate in US manufacturing has been quite volatile and procyclical. In particular, the estimates indicate that the estimated range of the depreciation rate of equipment capital in US manufacturing varies between $9.3 \%$ to $13.7 \%$ over the period $1958-2009$. The correlation with output trend is positive and amounts to $56 \%$ over the sample considered, a figure that is very close to the corresponding one for Canada.

These results shed some further light in the variability of capital depreciation, as few studies have focused on its behavior over time. Epstein and Denny (1980) report that the average depreciation rate in total US manufacturing over the period 1947-1971 ranged between $10.8 \%$ and $14.5 \%$. Kollintzas and Choi (1985) report a similar range of $10.7 \%-14.1 \%$ over the same time period, whereas Bischoff and Kokkelenberg report a range of 9.6-11.8\% over a period extended to 1978. In all these studies the general

\footnotetext{
${ }^{17}$ The series are obtained by multiplying the estimated maintenance to investment ratio by the estimated series of investments in levels.
} 
claim is that the depreication rate has been fairly stable over time, whereas Nadiri and Prucha (1996a) report that the constant depreciation rate assumption cannot be rejected for the US electrical machinery industry. Our evidence, based on machinery-equipment capital, generates a wider spread for capital depreciation, which is not unreasonable given the 50-year time span of our study. Importantly, our implied depreciation rate follows a highly procyclical pattern, a feature that has only been indirectly captured by Epstein and Denny (1980) for some cycles.

\section{Conclusions}

This paper formulated and estimated a DSGE business-cycle model in which the depreciation rate is endogenously determined by expenditures on capital maintenance, a feature that has been left unexplored in existing DSGE models. An important feature of our approach, apart from its general-equilibrium character, is that we were able to derive the cyclical movements of capital depreciation, in the absence of time-series data on capital maintenance that are largely unavailable. Our evidence on the time profile of the capital depreciation rate, which has been found to be procyclical and quite volatile, is contrasted to the standard assumption of constant capital depreciation, adopted routinely in most studies of macroeconomic fluctuations, and can provide significant insights in their sources and propagation mechanisms.

Our evidence may provide important potential insights for the tax treatment of capital assets and their depreciation. Given the procyclicality of depreciation, the state of the economy should be taken into account in the formation of the tax code and the calculation of variables affecting the values of assets, like interest rates. Nevertheless we emphasize that our implied estimates are in no way intended to provide definitive estimates of depreciation or their cyclical pattern. There is a great deal of room for further research, particularly in the areas of using more disaggregated data for the assessment of depreciation rates related to sectoral capital stocks within the context of a general equilibrium approach. Our findings should, thus, be viewed as an example of what can be achieved 
with a DSGE approach that accounts for capital maintenance. In this vein, the model can also be used to estimate unmeasured capital expenditures, like spending on capital maintenance, in other countries, as they form an important part of economic activity in order to estimate cross-country depreciation rates stemming from a general-equilibrium setup. 


\section{References}

[1] Basu, S. and M. S. Kimball, 1997. 'Cyclical productivity with unobserved input variation', NBER Working Paper 5915.

[2] Becker R.A. and W.B. Gray, 2009, NBER-CES Manufacturing Industry Database, available at http://www.nber.org/data/nbprod2005.html.

[3] Bischoff C.W. and E.C. Kokkelenerg, 1987, 'Capacity utilization and depreciationin-use', Applied Economics, 19(8), 995-1007.

[4] Bitros G., 1976, 'A statistical theory of expenditures in capital maintenance and repair', Journal of Political Economy, 84(5), 917-936

[5] Boucekkine R. and R. Ruiz-Tamarit, 2003, 'Capital maintenance and investment: complements or substitutes?', Journal of Economics, 78(1), 1-28.

[6] Boucekkine R., F. del Rio and B. Martinez, 2009, 'Technological progress, obsolescence, and depreciation', Oxford Economic Papers, 61(3), 440-466.

[7] Boucekkine R., G. Fabbri, F. Gozzi, 2010, 'Maintenance and investment: complements or substitutes? A reappraisal', Journal of Economic Dynamics and Control, 34(12), 2420-2439.

[8] Brooks S.P. and A. Gelman, 1998, 'General Methods for monitoring convergence of iterative simulations', Journal of Computational and Graphical Statistics, 7(4), 434-455.

[9] Burnside C. and M. Eichenbaum, 1996, 'Factor-hoarding and the propagation of business-cycle shocks', American Economic Review, 86(5), 1154-1174.

[10] Casares M. and B.T. McCallum, 2006, 'An optimizing IS-LM framework with endogenous investment', Journal of Macroeconomics, 28(4), 621-644.

[11] Chen K., A. Imrohoroglu and S. Imrohoroglu, 2006, 'The Japanese saving rate', American Economic Review, 86(5), 1850-1858. 
[12] Collard F. and T. Kollintzas, 2000, 'Maintenance, utilization, and depreciation along the business cycle', CEPR Discussion Paper No. 2477.

[13] Epstein L. and M. Denny, 1980, 'Endogenous capital utilization in a short-run production function', Journal of Econometrics, 12(2), 189-207.

[14] Evers M., R.A. De Mooij and D.J. Van Vuuren, 2008, 'The wage elasticity of labor supply: a synthesis of empirical estimates?', De Economist, 156(1), 25-43.

[15] Feldstein M. and D. Foot, 1971, 'The other half of gross investment: Replacement and modernization expenditures', Review of Economics and Statistics, 53(1), 49-58.

[16] Fisher J., 2006, 'The dynamic effects of neutral and investment-specific technology shocks', Journal of Political Economy, 114(3), 413-451.

[17] Fraumeni B.M., 1997, 'The measurement of depreciation in the U.S. National Income and Product Accounts', Survey of Current Business, July, 7-23.

[18] Furlanetto, F. and M. Seneca, 2013. 'New perspectives on depreciation shocks as a source of business cycle fluctuations', Macroeconomic Dynamics, forthcoming.

[19] Greenwood J., Z. Hercowitz and G. Huffman, 1988, 'Investment, capacity utilization, and the business cycle', American Economic Review, 78(3), 402-417.

[20] Greenwood J., Z. Hercowitz and P. Krusell, 1997, 'Long-run implications of investment-specific technological change', American Economic Review, 87(3), 342-362.

[21] Greenwood J., Z. Hercowitz and P. Krusell, 2000, 'The role of investment-specific technological change in the business cycle', European Economic Review, 44(1), 91-115.

[22] Huang N. and E. Diewert, 2011, 'Estimation of R\&D depreciation rates: a suggested methodology and preliminary application', Canadian Journal of Economics, 44(2), 387-412.

[23] Hulten C.R. and F.C. Wykoff, 1981a, 'The estimation of economic depreciation using vintage asset prices: An application of the Box-Cox power transformation', 
Journal of Econometrics, 15(3), 367-396.

[24] Hulten C.R. and F.C. Wykoff, 1981b, 'The measurement of economic depreciation', in C.R. Hulten (ed.), Depreciation, Inflation, and the Taxation of Income from Capital, The Urban Institute: Washington D.C. (81-125).

[25] Hwang J.C., 2002/3, 'Forms and rates of economic and physical depreciation by type of assets in Canadian Industries', Journal of Economic and Social Measurement, 28, 89-108.

[26] Jorgenson D.W., 1996, 'Empirical studies of depreciation', Economic Inquiry, 34(1), 24-42.

[27] Kollintzas T. and J. Choi, 1985, 'A linear rational expectations equilibrium model of aggregate investment with endogenous capital utilization and maintenance', Working Paper No 182, Department of Economics, University of Pittsburg.

[28] Licandro O. and L.A. Puch, 2000, 'Capital utilization, maintenance costs and the business cycle', Annales d'Economie et de Statistique, 58, 143-164.

[29] Liu Z., D. Waggoner and T. Zha, 2011, 'Sources of macroeconomic fluctuations: A regime-switching DSGE approach', Quantitative Economics, 2(2), 251-301.

[30] McGrattan E. and J. Schmitz, 1999, 'Maintenance and repair: Too big to ignore', Federal Reserve Bank of Minneapolis Quarterly Review, 23(4), 2-13.

[31] Nadiri I. and I. Prucha, 1996a, 'Endogenous capital utilization and productivity measurement in dynamic factor demand models: Theory and an application to the US electrical machinery industry', Journal of Econometrics, 71(1-2), 343-379.

[32] Nadiri I. and I. Prucha, 1996b, 'Estimation of depreciation rate of physical and R\&D capital in the US total manufacturing sector', Economic Inquiry, 34(1), 43-56.

[33] Nelson R. and M. Caputo, 1997, 'Price changes, maintenance, and the rate of depreciation', Review of Economics and Statistics, 79(3), 422-30.

[34] Neiss K. and E. Pappa, 2005, 'Persistence without too much price stickiness: the role of variable factor utilization', Review of Economic Dynamics, 8(1), 231-255. 
[35] Nickell S., 1978, The Investment Decisions of Firms, Oxford: Cambridge University Press.

[36] Parks R., 1979, 'Durability, maintenance and the price of used assets', Economic Inquiry, 17(2), 197-217.

[37] Saglam C. and V.M. Veliov, 2008. 'Role of endogenous vintage specific depreciation in the optimal behavior of firms', International Journal of Economic Theory, 4(3), $381-410$.

[38] Schmalensee R., 1974, 'Market structure, durability, and maintenance effort', Review of Economic Studies, 41(2), 277-87.

[39] Schworm W., 1979, 'Tax policy, capital use, and investment incentives', Journal of Public Economics, 12(2), 191-204.

[40] Sims C., 1999, Matlab Optimization Software, Quantitative Macroeconomics $\&$ Real Business Cycles.

[41] Smets F. and R. Wouters, 2007, 'Shocks and frictions in US business cycles: A Bayesian DSGE approach', American Economic Review, 97(3), 586-606.

[42] Woodford M., 2003, Interest and Prices: Foundations of a Theory of Monetary Policy, Princeton: Princeton University Press. 
Table 1: Calibrated parameters and steady-state values

\begin{tabular}{|c|c|c|}
\hline \hline parameter & description & steady-state value \\
\hline$\beta$ & discount factor & 0.98 \\
$I / K$ & investment to capital ratio & 0.0882 (Canada), 0.1170 (US) \\
$M / K$ & maintenance to capital ratio & 0.0494 (Canada), 0.0309 (US) \\
$\delta$ & depreciation & $I / K$ \\
$M / I$ & maintenance to investment ratio & $\frac{M}{K} / \frac{I}{K}$ \\
$r^{*}$ & net real interest rate & $(1 / \beta)-1+I / K+M / K$ \\
$Y / K$ & output to capital ratio & $r^{*} /(1-\alpha)$ \\
$Y / I$ & output to investment ratio & $\frac{Y}{K} / \frac{I}{K}$ \\
$G / Y$ & public spending to output ratio & 0.17 \\
$G / K$ & public spending to capital ratio & $G / Y * Y / K$ \\
$C / K$ & consumption to capital ratio & $Y / K-I / K-M / K-G / K$ \\
$C / I$ & consumption to investment ratio & $\frac{C}{K} / \frac{I}{K}$ \\
$M / Y$ & maintenance to output ratio & $\frac{M}{K} / \frac{Y}{K}$ \\
$Z$ & investment specific technology & 1 \\
$X$ & TFP & 1 \\
\hline \hline
\end{tabular}


Table 2: Prior distribution of structural parameters and shock processes

\begin{tabular}{|c|ccccc|}
\hline \hline parameter & prior & prior mean & prior std deviation & lower bound & upper bound \\
\hline \hline$\gamma$ & Normal & 10 & 10 & & \\
$\phi$ & Gamma & 0.9 & 0.2 & 0 & 10 \\
$b$ & Normal & 0 & 4 & 0.01 & 6 \\
$\sigma$ & Normal & 2 & 3 & 0.01 & 10 \\
$\theta_{n}$ & Normal & 1.25 & 2 & 0.01 & 1 \\
$\alpha$ & Normal & 0.7 & 0.05 & 0.01 & 0.99 \\
$\rho_{x}$ & Beta & 0.5 & 0.2 & 0.01 & 0.99 \\
$\rho_{z}$ & Beta & 0.5 & 0.2 & 0.01 & 0.99 \\
$\rho_{u}$ & Beta & 0.5 & 0.2 & 0.01 & 0.99 \\
$\rho_{h}$ & Beta & 0.5 & 0.2 & 0.01 & 0.99 \\
$\rho_{g}$ & Beta & 0.5 & 0.2 & 0.01 & 3 \\
$\sigma_{x}$ & Inv-gamma & 0.1 & Inf & 0.01 & 3 \\
$\sigma_{z}$ & Inv-gamma & 0.1 & Inf & 0.01 & 3 \\
$\sigma_{u}$ & Inv-gamma & 0.1 & Inf & 0.01 & 3 \\
$\sigma_{h}$ & Inv-gamma & 0.1 & Inf & 0.01 & 3 \\
$\sigma_{g}$ & Inv-gamma & 0.1 & Inf & & \\
\hline \hline
\end{tabular}


Table 3: Posterior distributions of structural parameters and shock processes of the models for Canada and US

\begin{tabular}{|c|c|c|c|c|c|c|c|c|}
\hline \multirow{3}{*}{$\begin{array}{c}\text { country } \\
\text { model } \\
\text { parameter }\end{array}$} & \multicolumn{4}{|c|}{ Canada } & \multicolumn{4}{|c|}{ US } \\
\hline & \multicolumn{2}{|c|}{ standard model } & \multicolumn{2}{|c|}{ maintenance model } & \multicolumn{2}{|c|}{ standard model } & \multicolumn{2}{|c|}{ maintenance model } \\
\hline & post. mean & conf. interval & post. mean & conf. interval & post. mean & conf. interval & post. mean & conf. interval \\
\hline$\gamma$ & & & 19.19 & $8.37 ; 29.79$ & & & 8.79 & $3.92 ; 13.99$ \\
\hline$\phi$ & 2.21 & $1.64 ; 2.75$ & 1.08 & $0.76 ; 1.40$ & 1.71 & $1.40 ; 2.02$ & 0.82 & $0.66 ; 0.97$ \\
\hline$b$ & 9.02 & $7.83 ; 10.00$ & 8.67 & $7.16 ; 10.00$ & 6.64 & $4.71 ; 8.55$ & 7.13 & $5.30 ; 9.08$ \\
\hline$\sigma$ & 2.70 & $1.59 ; 3.80$ & 3.20 & $1.82 ; 4.54$ & 1.42 & $1.12 ; 1.71$ & 1.54 & $1.21 ; 1.87$ \\
\hline$\theta_{n}$ & 2.11 & $0.76 ; 3.44$ & 2.05 & $0.71 ; 3.40$ & 0.33 & $0.06 ; 0.57$ & 0.34 & $0.05 ; 0.60$ \\
\hline$\alpha$ & 0.70 & $0.63 ; 0.78$ & 0.75 & $0.68 ; 0.82$ & 0.78 & $0.71 ; 0.85$ & 0.78 & $0.71 ; 0.85$ \\
\hline$\rho_{x}$ & 0.54 & $0.34 ; 0.74$ & 0.53 & $0.33 ; 0.73$ & 0.47 & $0.26 ; 0.69$ & 0.45 & $0.25 ; 0.65$ \\
\hline$\rho_{z}$ & 0.50 & $0.30 ; 0.73$ & 0.54 & $0.29 ; 0.77$ & 0.38 & $0.17 ; 0.58$ & 0.39 & $0.19 ; 0.58$ \\
\hline$\rho_{u}$ & 0.47 & $0.29 ; 0.65$ & 0.46 & $0.28 ; 0.65$ & 0.55 & $0.38 ; 0.72$ & 0.56 & $0.39 ; 0.73$ \\
\hline$\rho_{h}$ & 0.72 & $0.58 ; 0.86$ & 0.72 & $0.58 ; 0.85$ & 0.55 & $0.34 ; 0.75$ & 0.57 & $0.37 ; 0.78$ \\
\hline$\rho_{g}$ & 0.48 & $0.31 ; 0.66$ & 0.50 & $0.32 ; 0.67$ & 0.36 & $0.18 ; 0.54$ & 0.37 & $0.18 ; 0.55$ \\
\hline$\sigma_{x}$ & 0.030 & $0.024 ; 0.035$ & 0.029 & $0.024 ; 0.034$ & 0.040 & $0.033 ; 0.046$ & 0.040 & $0.033 ; 0.046$ \\
\hline$\sigma_{z}$ & 0.056 & $0.038 ; 0.073$ & 0.062 & $0.047 ; 0.077$ & 0.036 & $0.026 ; 0.046$ & 0.047 & $0.034 ; 0.060$ \\
\hline$\sigma_{u}$ & 0.104 & $0.081 ; 0.127$ & 0.146 & $0.113 ; 0.180$ & 0.087 & $0.064 ; 0.109$ & 0.090 & $0.067 ; 0.112$ \\
\hline$\sigma_{h}$ & 0.091 & $0.045 ; 0.136$ & 0.096 & $0.049 ; 0.144$ & 0.033 & $0.024 ; 0.042$ & 0.035 & $0.025 ; 0.046$ \\
\hline$\sigma_{g}$ & 0.215 & $0.178 ; 0.249$ & 0.214 & $0.178 ; 0.248$ & 0.193 & $0.162 ; 0.223$ & 0.183 & $0.151 ; 0.214$ \\
\hline
\end{tabular}


Table 4: Estimated depreciation rate of equipment capital in Canadian manufacturing (1956-2005)

\begin{tabular}{|cc|cc|}
\hline \hline year & depreciation rate & year & depreciation rate \\
\hline 1956 & 0.0778 & 1981 & 0.0932 \\
1957 & 0.0897 & 1982 & 0.0540 \\
1958 & 0.0983 & 1983 & 0.0641 \\
1959 & 0.0888 & 1984 & 0.0936 \\
1960 & 0.0912 & 1985 & 0.1077 \\
1961 & 0.0920 & 1986 & 0.0979 \\
1962 & 0.0774 & 1987 & 0.1003 \\
1963 & 0.0811 & 1988 & 0.0957 \\
1964 & 0.0933 & 1989 & 0.0896 \\
1965 & 0.1044 & 1990 & 0.0797 \\
1966 & 0.1005 & 1991 & 0.0667 \\
1967 & 0.0837 & 1992 & 0.0759 \\
1968 & 0.0866 & 1993 & 0.0887 \\
1969 & 0.0951 & 1994 & 0.1002 \\
1970 & 0.0698 & 1995 & 0.0980 \\
1971 & 0.0746 & 1996 & 0.0918 \\
1972 & 0.0854 & 1997 & 0.0922 \\
1973 & 0.1075 & 1998 & 0.0933 \\
1974 & 0.1034 & 1999 & 0.0954 \\
1975 & 0.0728 & 2000 & 0.0955 \\
1976 & 0.0850 & 2001 & 0.0803 \\
1977 & 0.0921 & 2002 & 0.0839 \\
1978 & 0.1063 & 2003 & 0.0785 \\
1979 & 0.1132 & 2004 & 0.0894 \\
1980 & 0.0903 & 2005 & 0.0928 \\
\hline \hline
\end{tabular}


Table 5: Estimated capital maintenance (in current million USD) and depreciation rates of equipment capital in US manufacturing (1958-2009)

\begin{tabular}{|ccc|ccc|}
\hline \hline year & maintenance & depreciation rate & year & maintenance & depreciation rate \\
\hline 1958 & 1881 & 0.1069 & 1984 & 14827 & 0.1255 \\
1959 & 2079 & 0.1273 & 1985 & 15471 & 0.1178 \\
1960 & 2135 & 0.1180 & 1986 & 17091 & 0.1140 \\
1961 & 2227 & 0.1042 & 1987 & 21272 & 0.1162 \\
1962 & 2397 & 0.1151 & 1988 & 22052 & 0.1263 \\
1963 & 2612 & 0.1181 & 1989 & 21781 & 0.1242 \\
1964 & 3046 & 0.1201 & 1990 & 19838 & 0.1219 \\
1965 & 3313 & 0.1324 & 1991 & 19399 & 0.1108 \\
1966 & 3718 & 0.1369 & 1992 & 22924 & 0.1107 \\
1967 & 4230 & 0.1201 & 1993 & 22746 & 0.1148 \\
1968 & 4780 & 0.1197 & 1994 & 23365 & 0.1215 \\
1969 & 5044 & 0.1205 & 1995 & 26890 & 0.1242 \\
1970 & 5193 & 0.0989 & 1996 & 25331 & 0.1250 \\
1971 & 5651 & 0.0952 & 1997 & 33013 & 0.1223 \\
1972 & 6288 & 0.1141 & 1998 & 38225 & 0.1140 \\
1973 & 6364 & 0.1369 & 1999 & 39266 & 0.1117 \\
1974 & 6789 & 0.1305 & 2000 & 31624 & 0.1200 \\
1975 & 7143 & 0.0948 & 2001 & 27804 & 0.1037 \\
1976 & 8937 & 0.1087 & 2002 & 31292 & 0.0988 \\
1977 & 10551 & 0.1236 & 2003 & 27813 & 0.1080 \\
1978 & 12080 & 0.1318 & 2004 & 28195 & 0.1188 \\
1979 & 13642 & 0.1332 & 2005 & 30620 & 0.1281 \\
1980 & 12178 & 0.1221 & 2006 & 32010 & 0.1315 \\
1981 & 12848 & 0.1184 & 2007 & 34609 & 0.1352 \\
1982 & 13157 & 0.0966 & 2008 & 25504 & 0.1331 \\
1983 & 13357 & 0.1061 & 2009 & 29950 & 0.0929 \\
\hline \hline
\end{tabular}


Figure 1: Maintenance, capital and output: Canada, 1956-2005.

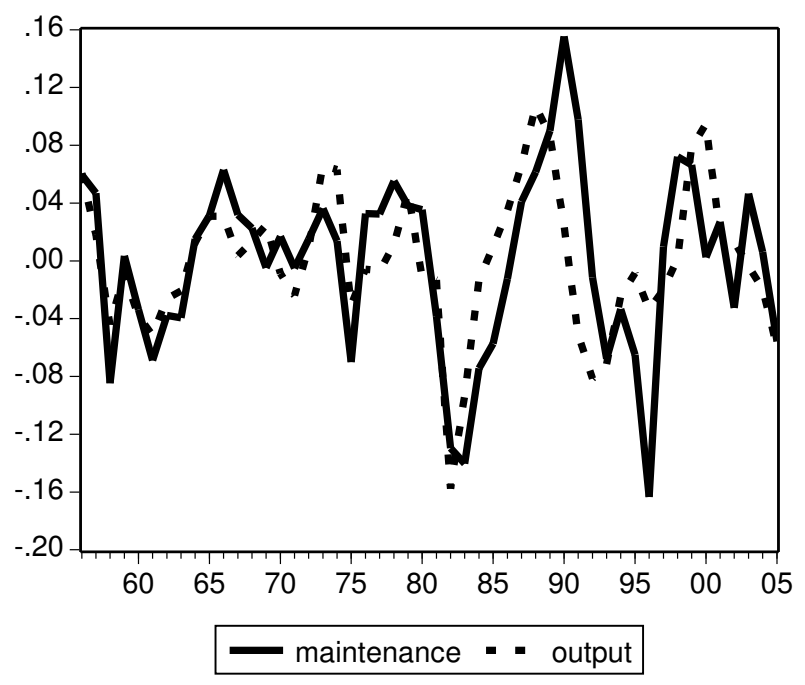

(a) Maintenance vs output

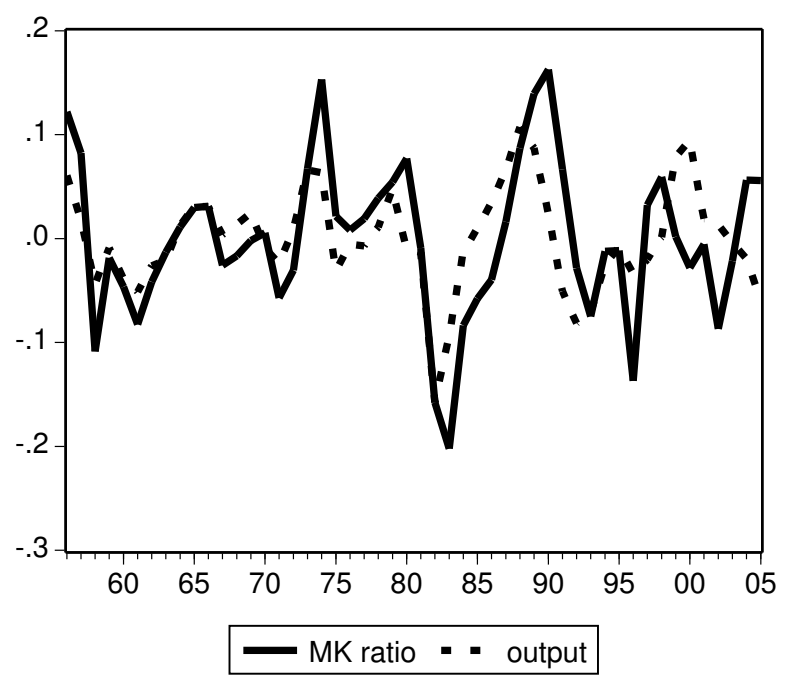

(b) Maintenance to capital ratio vs output 
Figure 2: Impulse responses of variables to all shocks (in rows).
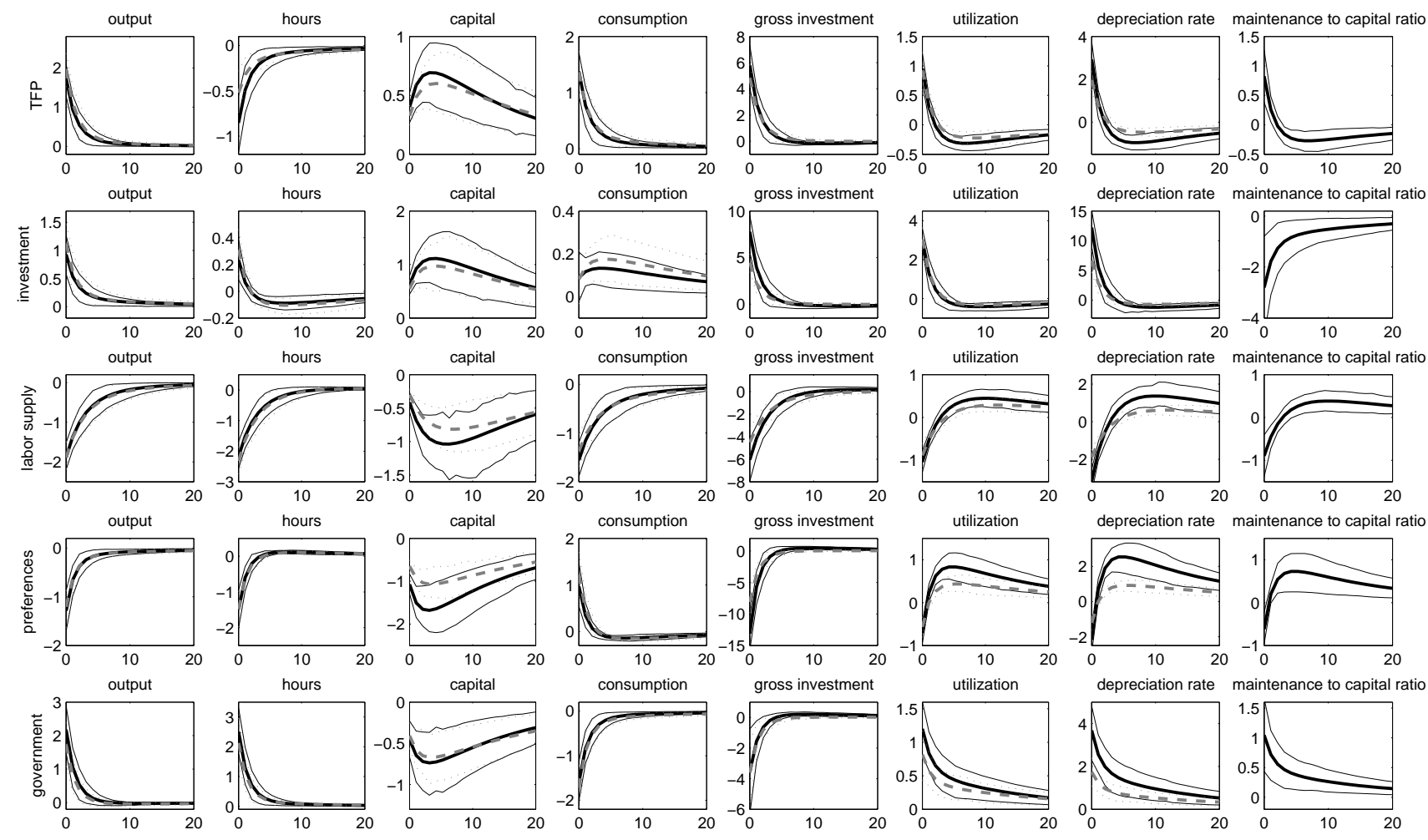

Note: solid black line for endogenous maintenance model, dashed grey line for standard RBC model. 
Figure 3: Estimated MK ratio: Canada, 1956-2005.

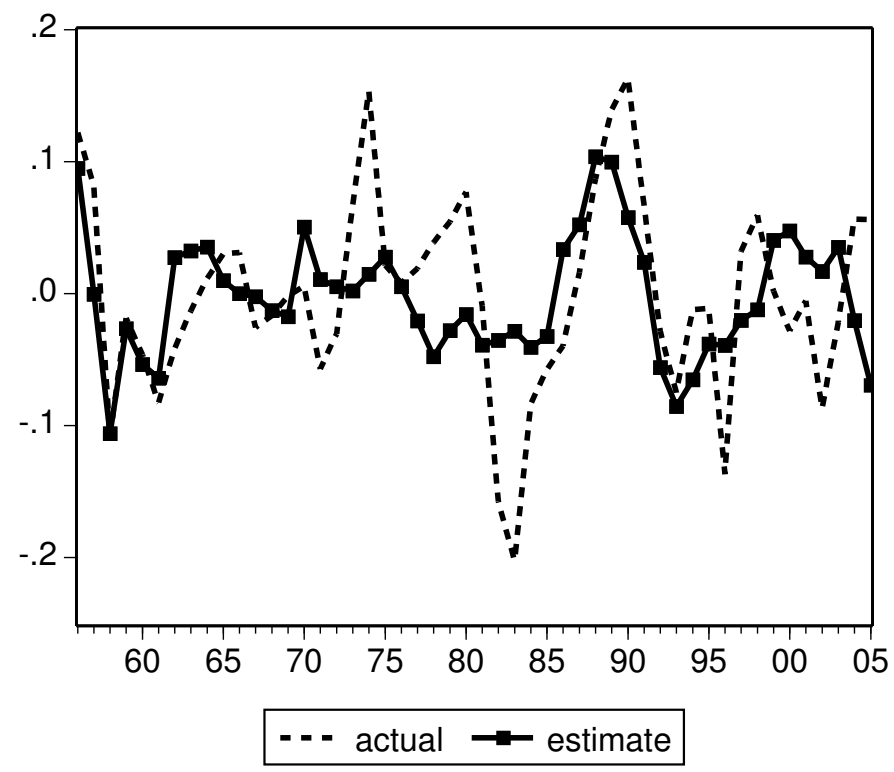

Figure 4: Actual and estimated maintenance to 'new' investment ratio: Canada, 19562005 .

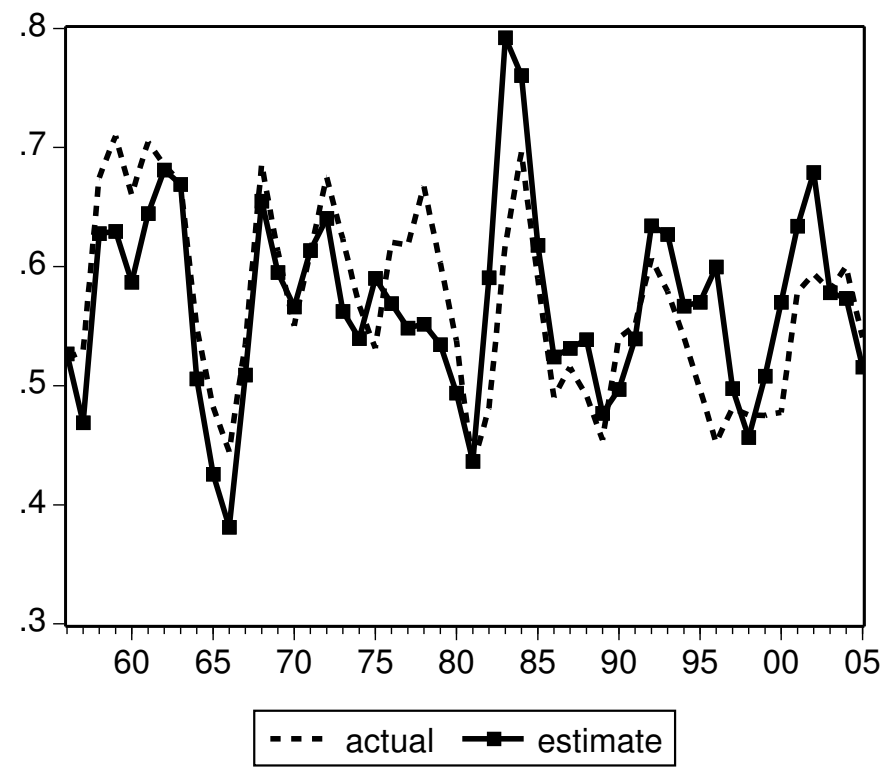


Figure 5: Output (trend deviations) and estimated depreciation rate (equipment capital): Canadian manufacturing, 1956-2005.

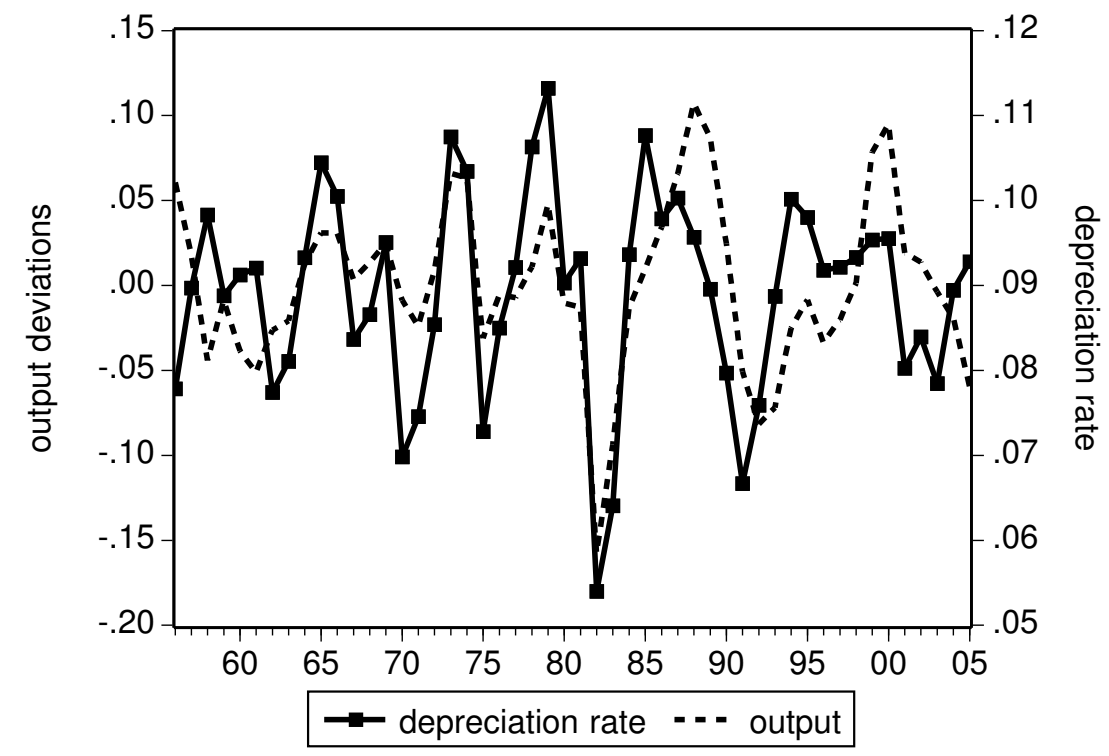

Figure 6: Estimated capital maintenance and output (trend deviations) in US manufacturing

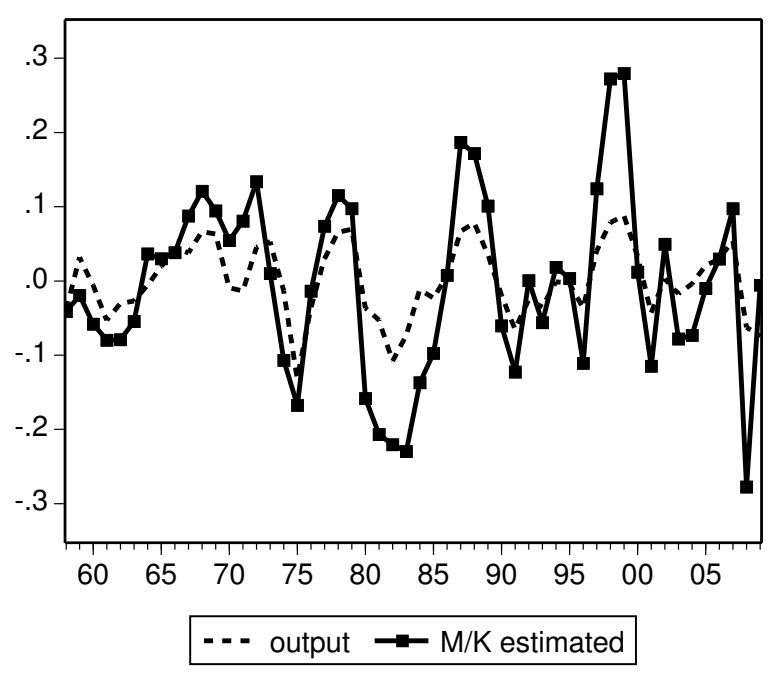


Figure 7: Estimated maintenance to 'new' investment ratio and output (trend deviations) in US manufacturing

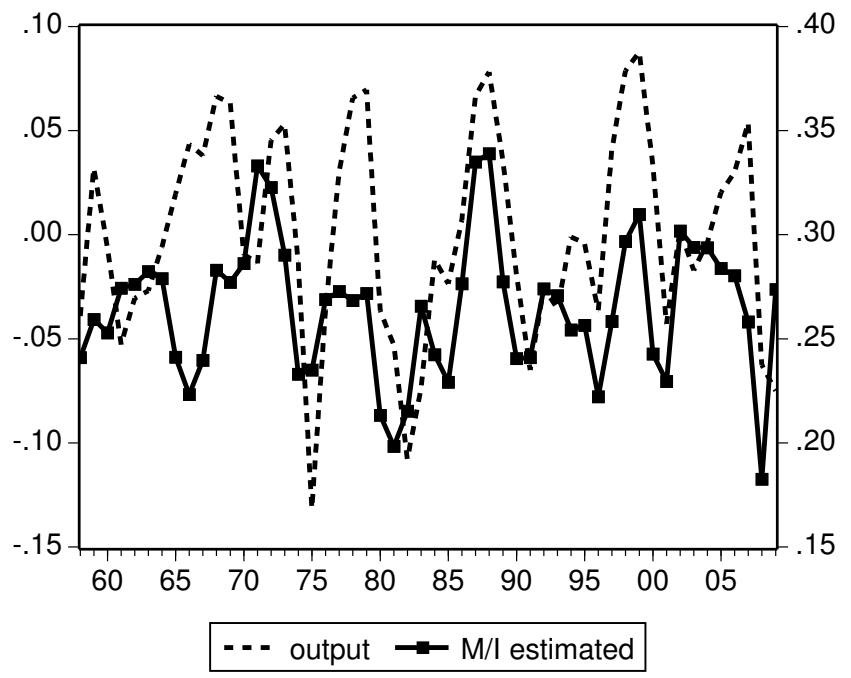

Figure 8: Output (trend deviations) and depreciation rate: US manufacturing capital (equipment and structures)

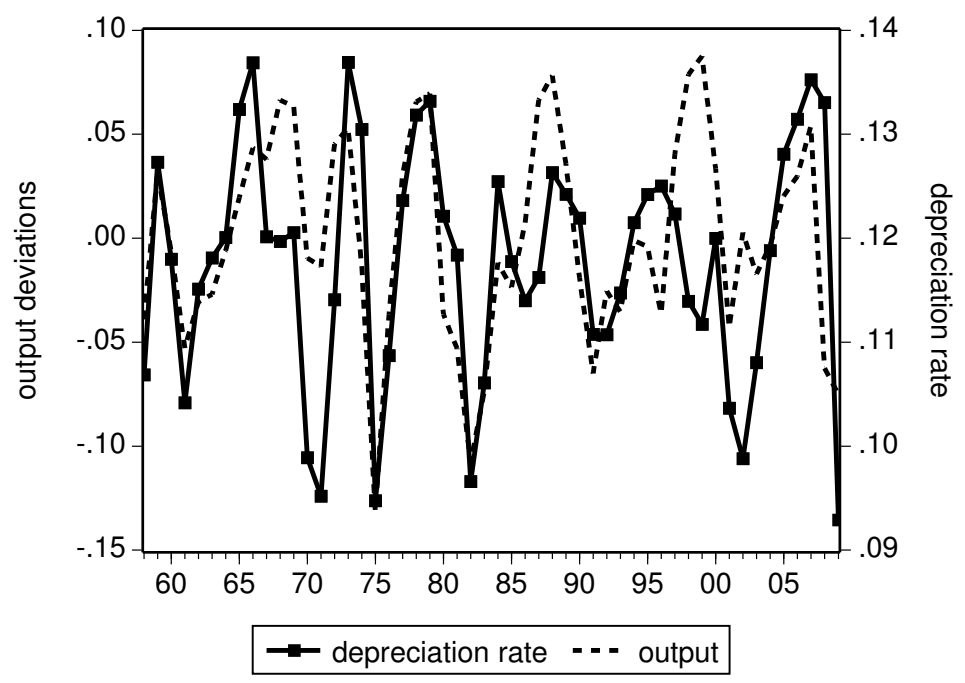

